\section{Reversible male subfertility due to hyperthyroidism}

Hyperthyroidism in women may cause oligomenorrhoea, amenorrhoea, and failure of ovulation. In men gonadal dysfunction is less apparent, though loss of libido, reduced potency, ${ }^{1}$ and gynaecomastia ${ }^{2}$ may occur. We describe a man who presented with subfertility due to thyrotoxicosis and in whom normal fertility was restored with antithyroid drug treatment.

\section{Case report}

A 26-year-old man with a one-year history of attempted conception was referred to a male subfertility clinic. Two previous semen analyses had disclosed oligospermia with sperm counts of $11 \times 10^{9} / 1$ on both occasions (figure). He had had classical symptoms of thyrotoxicosis for five years and 18 months earlier had been investigated for palpitations.

Examination showed a diffuse goitre, tremor, and tachycardia; vitiligo was present on the arms, trunk, and penis. There was no gynaecomastia and the testes were normal. Hyperthyroidism was confirmed biochemically: serum thyroxine concentration was $267 \mathrm{mmol} / 1(20.7 \mu \mathrm{g} / 100 \mathrm{ml}$ ) (normal range $70-160 \mathrm{mmol} / 1 ; 5 \cdot 4-12 \cdot 4 \mu \mathrm{g} / 100 \mathrm{ml}$ ) and free thyroxine index $>500$ (normal range 70-180). Basal serum luteinising hormone, follicle-stimulating hormone, and prolactin concentrations were normal. Serum testosterone concentration was considerably raised at $68.9 \mathrm{nmol} / 1(1.9 \mu \mathrm{g} / \mathrm{ml}$ ) (normal range $10-35 \mathrm{nmol} / 1 ; 0 \cdot 2-1 \cdot 0 \mu \mathrm{g} / \mathrm{ml}$ ). Restoration of normal thyroid function with treatment with carbimazole therapy was associated with a fall in serum testosterone concentration to $20.5 \mathrm{mmol} / 1(591 \mathrm{mg} / 100 \mathrm{ml})$ and a progressive increase in sperm count. After 12 months of treatment his wife conceived and subsequently gave birth to a normal son.
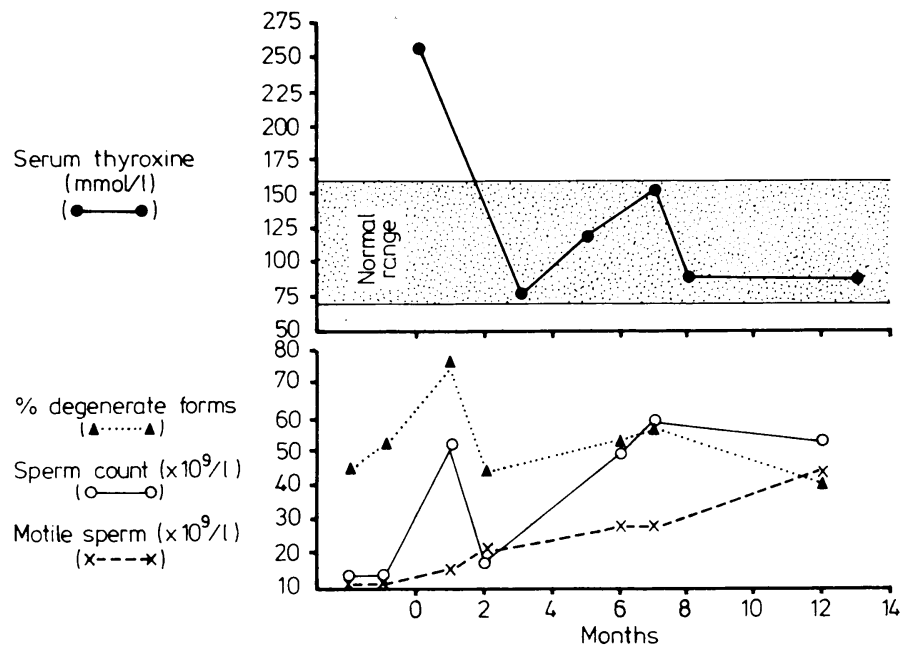

Response of serum thyroxine concentration, sperm count, motile sperm and $\%$ degenerate forms to treatment with carbimazole starting at month 0 , Conversion: SI to traditional units-serum thyroxine: $1 \mathrm{mmol} / 1 \approx 0.05 \mu \mathrm{g} /$ $100 \mathrm{ml}$.

\section{Comment}

Thyrotoxic men may have reduced potency and libido, ${ }^{1}$ but subfertility as a presenting complaint is extremely unusual. Oligospermia has been reported previously, ${ }^{13}$ and in one subject with oligospermia testicular biopsy showed arrest of maturation at the primary spermatocyte stage. ${ }^{3}$ While there is no evidence for a direct effect of thyroid hormones on the testis in man, an indirect effect on spermatogenesis is possible through an increase in body temperature. Thyroid-stimulating immunoglobulins may affect spermatogenesis by binding to testicular receptors of thyroid-stimulating hormone. The role of these in testicular physiology is, however, not yet known.

Although the mechanism of suppression of spermatogenesis in thyrotoxicosis is unknown, changes in androgen, oestrogen, and gonadotrophin physiology have been described. One of the most striking changes is the distinct rise in serum total testosterone con- centration $^{45}$ due to an increase in sex-hormone-binding globulin. Free hormone concentration is, however, normal. ${ }^{4}$ Plasma oestradiol concentration is also increased in most patients, ${ }^{4}$ and there is enhanced peripheral conversion of androgen to oestrogen. Serum free oestradiol concentrations are raised and may approximate to those found in normal women in the follicular phase of the menstrual cycle. ${ }^{4}$ Gynaecomastia, which occurs especially in those with high sexhormone-binding globulin and free oestradiol concentrations, ${ }^{4}$ is detectable clinically in up to $40 \%$ of cases and by histological criteria in a higher percentage. ${ }^{2}$ Despite these changes, basal serum gonadotrophin values are normal or raised and the response to injected luteinising hormone releasing hormone is normal. ${ }^{1}$ Basal serum prolactin concentration is normal, but the response to thyrotrophinreleasing hormone is diminished, returning to normal with successful treatment of the thyrotoxicosis.

Thyrotoxicosis is an unusual cause of male subfertility: this common endocrine disorder should be considered in this context for, as the present case shows, treatment may be successful in restoring normal fertility.

${ }^{1}$ Kidd GS, Glass AR, Vigersky RA. The hypothalamic-pituitary-testicular axis in thyrotoxicosis. F Clin Endocrinol Metab 1979;48:798-802.

${ }^{2}$ Becker KL, Matthews MJ, Higgins GA, Mohamadi M. Histologic evidence of gynecomastia in hyperthyroidism. Arch Pathol 1974;98: 257-60.

${ }^{3}$ Clyde HR, Walsh PC, English RW. Elevated plasma testosterone and gonadotropin levels in infertile males with hyperthyroidism. Fertil Steril 1976;27:662-6.

${ }^{4}$ Chopra IJ, Tulchinsky D. Status of estrogen-androgen balance in hyperthyroid men with Graves' disease. F Clin Endocrinol Metab 1974;38: 269-77.

5 Tulchinsky D, Chopra IJ. Competitive ligand-binding assay for measurement of sex-hormone binding globulin (SHBG). $\mathcal{f}$ Clin Endocrinol Metab $1973 ; 37: 873-81$.

(Accepted 28 May 1982)

Department of Medicine, Bristol Royal Infirmary, Bristol BS2 8HW I A D O'BRIEN, MB, MRCP, research registrar

I G LEWIN, MB, MRCP, senior registrar

J P O'HARE, MB, MRCP, senior house officer

R J M CORRALL, MD, MRCP, consultant physician

\section{Atenolol: side effects in a newborn infant}

Beta-adrenergic-blocking agents have been recommended for the management of maternal hypertension during pregnancy. Propranolol, a non-cardioselective beta-blocking agent, was used initially but later abandoned owing to the unacceptably high incidence of bradycardia, hypoglycaemia, and hypotension induced in the newborn infant. Recently cardioselective beta-blocking agents such as oxprenolol, acebutolol, and atenolol have been advocated; though they may also produce bradycardia and hypotension in the infant at birth. ${ }^{2}$

Atenolol has a relatively long half life and needs to be administered only once daily. ${ }^{3}$ Its use during pregnancy has been incompletely documented. We report the clinical findings, together with serum and urine drug concentrations, in an infant born to a hypertensive woman treated with atenolol.

\section{Case report}

A 30-year-old multigravid woman with uncontrolled hypertension was delivered by caesarean section at 38 weeks' gestation. She weighed $64 \mathrm{~kg}$ and had been treated for three days with oral atenolol, $100 \mathrm{mg}$ daily and phenobarbitone $30 \mathrm{mg}$ eight-hourly. The infant weighed $2680 \mathrm{~g}$ and had one- and five-minute Apgar scores of 8 and 10 respectively with a crying pulse rate of 130 beats/minute. The maternal plasma atenolol concentration was $0 \cdot 145$ $\mu \mathrm{g} / \mathrm{ml}$ and the umbilical vein concentration $0.314 \mu \mathrm{g} / \mathrm{ml}$.

Immediately after birth the infant appeared normal and was nursed in a closed incubator. Small milk feeds were started. Fifteen hours after delivery, however, he developed peripheral cyanosis and a prolonged capillary-filling 
time. Crying pulse was 138 beats/minute and systolic blood pressure $40 \mathrm{~mm}$ $\mathrm{Hg}$. There was no respiratory distress or evidence of congestive cardiac failure. No urine had been passed since delivery. Abdominal skin temperature was $35.4^{\circ} \mathrm{C}$ and blood glucose concentration $2.5 \mathrm{mmol} / 1(45 \mathrm{mg} / 100 \mathrm{ml})$ by the Dextrostix method. Plasma atenolol concentration was $0 \cdot 240 \mu \mathrm{g} / \mathrm{ml}$. Betablockade was diagnosed and $10 \mathrm{ml}$ plasma $/ \mathrm{kg}$ infused intravenously. Peripheral perfusion improved dramatically and systolic blood pressure increased to $55 \mathrm{~mm} \mathrm{Hg}$. Soon afterwards urine with an atenolol concentration of $0.620 \mu \mathrm{g} / \mathrm{ml}$ was passed. A slow intravenous infusion of glucose and electrolytes was then started. Thereafter his general condition remained satisfactory, with a sleeping pulse of 128 and a crying pulse of 138 beats/minute. No antibiotics were prescribed. After 12 hours the infusion was stopped and he was transferred to an open crib.

On the second day he appeared clinically normal with a good urine output. Sleeping and crying pulse rates were 124 and 140 beats/minute respectively. The atenolol concentration in a random urine sample was $0.435 \mu \mathrm{g} / \mathrm{ml}$. On the seventh day, when the mother and infant were discharged, his sleeping pulse had increased to 140 beats/minute. Atenolol concentrations in random samples of urine on days $3,4,5,6$, and 7 were $0.810,0.850,0.275$, and $0 \cdot 196 \mu \mathrm{g} / \mathrm{ml}$ respectively.

\section{Comment}

The infant studied showed clinical signs suggestive of beta-blockade -namely, bradycardia both at rest and when crying and hypotension. In addition he developed hypothermia, poor peripheral perfusion, and oliguria. In view of the persistent bradycardia the beta-blockade was probably operative for a few days after delivery. Certainly atenolol excretion in the urine was protracted with appreciable concentrations being present up to the seventh day, when he was discharged. The delayed atenolol clearance was presumably due to the decreased glomerular filtration rate that characterises the first week of life.

There is also evidence of fetal drug accumulation; high fetomaternal atenolol ratios have been described, ${ }^{4}$ while the ratio in our infant was $2: 2$. This high ratio could be accounted for by differences in plasma binding, drug ionisation, or some other impediment to free diffusion across the placenta. In any event the atenolol concentration of 0.314 $\mu \mathrm{g} / \mathrm{ml}$ in the umbilical vein falls within the therapeutic range for nonpregnant adults. ${ }^{3}$

Atenolol depends on urinary excretion of the unchanged drug as a means of whole body clearance; because this is impaired in the newborn infant use of atenolol before delivery should be questioned. If a cardioselective blocking agent is prescribed to treat hypertension during pregnancy we suggest that a short-acting agent is chosen.

1 Habib A, McCarthy JS. Effects on the neonate of propranolol administered during pregnancy. $\mathcal{F}$ Pediatr 1977;91:808-11.

2 Dumez Y, Tchobroutsky C, Hornrych H, Amiel-Tison C. Neonatal effects of maternal administration of acebutolol. Br Med 71981 ;283:1077-9.

3 Brown HC, Carruthers SG, Johnston GD, et al. Clinical pharmacologic observations on atenolol, a beta-adrenoreceptor blocker. Clin Pharmacol Ther 1976;20:524-34.

${ }^{4}$ Melander A, Niklasson B, Ingemarsson I, Liedholm H, Schersten B, Sjoberg NO. Transplacental passage of atenolol in man. Eur $\mathfrak{f}$ Clin Pharmacol 1978;14:93-4.

(Accepted 20 May 1982)

Departments of Paediatrics and Anaesthetics, University of Cape Town, Private Bag, Rondebosch 7700, Republic of South Africa

D L WOODS, MB, MRCP, consultant paediatrician

D F MORRELL, MB, FFA(SA), consultant anaesthetist

\section{Spontaneous gastric rupture complicating acute asthma}

Acute asthma may present a difficult management problem. We describe a patient who survived an asthmatic attack that was complicated by a spontaneous gastric rupture. The association between these two conditions has not been previously described.

\section{Case report}

A 51-year-old woman was admitted in August 1980 with an attack of asthma. She had first developed wheeze at the age of 16 and, though her symptoms were poorly controlled by inhalation of sodium cromoglycate and salbutamol, she had not required admission before for asthma and did not regularly attend an outpatient clinic. Her medical history included several admissions for minor tranquilliser overdoses and a traumatic pneumothorax.

On the day of admission she developed increasing wheeze. Her doctor prescribed $100 \mathrm{mg}$ hydrocortisone intravenously and arranged transport to hospital. During the ambulance journey she had a sudden onset of severe upper abdominal pain and felt nauseous. On arrival she was distressed and tachypnoeic with a tachycardia of 120 beats/min. Auscultation of her chest disclosed high-pitched expiratory rhonchi. Examination of her abdomen showed generalised tenderness and guarding with appreciable distension. Bowel sounds were absent.

Although her asthmatic attack responded promptly to intravenous aminophylline and nebulised salbutamol, the symptoms and signs persisted. An erect chest radiograph (figure) showed a large quantity of gas below both hemidiaphragms. Clinical and radiological findings indicated a tension pneumoperitoneum. To elucidate the diagnosis and to relieve the distension peritoneal lavage was performed using a peritoneal dialysis catheter inserted near the umbilicus. A large quantity of odourless gas escaped with relief to her respiration. The "wash back" was murky odourless fluid, suggesting perforation of the stomach or duodenum.

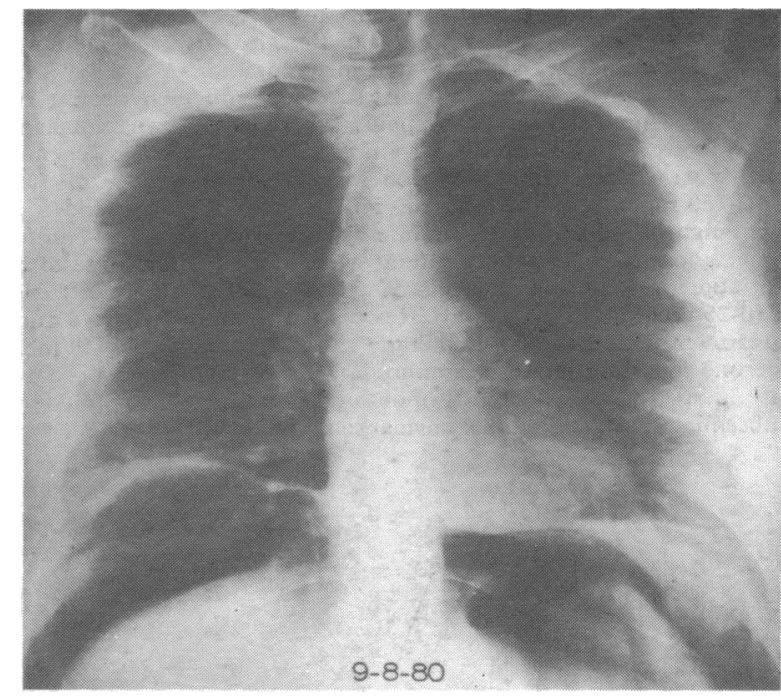

Erect chest radiograph showing large pneumoperitoneum.

Laparotomy showed gross contamination of the peritoneal cavity with gastric contents. A $3 \mathrm{~cm}$ longitudinal tear was found on the anterior aspect of the stomach near the mid-point of the lesser curve. There were no signs of peptic ulcer in the stomach or duodenum. The tear was repaired with chromic catgut and peritoneal toilet performed.

A mucosal biopsy specimen from the complete circumference of the tear showed the features of a subacute gastritis with no evidence of ulceration. Her postoperative recovery was complicated by a respiratory infection, but she was discharged, symptom free, 16 days after her operation. Her asthma remained poorly controlled but she had no obvious dyspeptic symptoms.

\section{Comment}

Spontaneous gastric rupture in an adult is rare and usually associated with severe retching, ${ }^{1}$ resuscitation using a tight-fitting face mask, ${ }^{2}$ mouth-to-mouth breathing, ${ }^{3}$ or nasal oxygen catheters. ${ }^{4}$ The mechanism of rupture appears to depend on a closed-loop obstruction in the stomach with considerable gastric dilatation that alters the gastro-oesophageal angle, preventing escape of gas back into the oesophagus. ${ }^{3}$ The distended stomach most commonly ruptures along the lesser curve. Perforation caused by repeated vomiting usually occurs along the greater curvature or fundus. ${ }^{1}$ As in most cases of spontaneous gastric rupture, our patient presented with a tension pneumoperitoneum. It occurred presumably with the massive gastric distension before rupture. A flap valve effect of the tear may have contributed further to the pneumoperitoneum.

Olsen and Foley suggested ${ }^{5}$ that some people are able to suck air into their oesophagus during inspiration by relaxation of their cricopharyngeal sphincter. They described gastric perforation in such a patient and coined the phrase "air-sucker's gastric rupture syndrome." If this was the mechanism of gastric dilatation in our patient then it would clearly be worsened by severe asthma. Increased respiratory effort would cause greater negative intra-oesophageal and intragastric pressures, which, with airways obstruction due to bronchoconstric- 